FACTA UNIVERSITATIS

Series: Mechanical Engineering Vol. 18, N ${ }^{\circ} 1,2020$, pp. 153 - 163

https://doi.org/10.22190/FUME190509032M

Original scientific paper

\title{
CFD MODELLING OF FORMULA STUDENT CAR INTAKE SYSTEM
}

\author{
Barhm Mohamad', Jalics Karoly ${ }^{1}$, Andrei Zelentsov ${ }^{2}$ \\ ${ }^{1}$ Faculty of Mechanical Engineering and Informatics, University of Miskolc, Hungary \\ ${ }^{2}$ Piston Engine Department, Bauman Moscow State Technical University, Russia
}

\begin{abstract}
Formula Student Car (FS) is an international race car design competition for students at universities of applied sciences and technical universities. The winning team is not the one that produces the fastest racing car, but the group that achieves the highest overall score in design, racing performance. The arrangement of internal components for example, predicting aerodynamics of the air intake system is crucial to optimizing car performance as speed changes. The air intake system consists of an inlet nozzle, throttle, restrictor, air box and cylinder suction pipes (runners). The paper deals with the use of CFD numerical simulations during the design and optimization of components. In this research article, two main steps are illustrated to develop carefully the design of the air box and match it with the suction pipe lengths to optimize torque over the entire range of operating speeds. Also the current intake system was assessed acoustically and simulated by means of 1-D gas dynamics using the software AVL-Boost. In this manner, before a new prototype intake manifold is built, the designer can save a substantial amount of time and resources. The results illustrate the improvement of simulation quality using the new models compared to the previous AVL-Boost models.
\end{abstract}

Key words: Internal combustion engine, Intake system, Linear acoustic, Geometry modification

\section{INTRODUCTION}

Each year the Formula Student (FS) hosts Colligate Design Competition for engineering students from around the world. The competition is judged based on engineering innovation, i.e. resulting performance and cost of a Formula style car designed to be produced in a small units production run. The objective of such a research work is to model and design Formula Student Car intake system and furthermore demonstrate new techniques to determine how those systems can be optimized in order to either increase the power of the car or reduce the sound level.

Received May 09, 2019 / Accepted October 08, 2019

Corresponding author: Barhm Mohamad

University of Miskolc, Faculty of Mechanical Engineering and Informatics, H-3515 Miskolc-Egyetemváros, Hungary

E-mail: vegybm@uni-miskolc.hu 
The intake system of an engine has three main functions. Its first and most identifiable function is air filtering the air in order to ensure the engine receives clean air free of debris. Two characteristics of importance to the engineers designing the intake system are its flow and acoustic performance. The flow efficiency of the intake system has a direct impact on the power the engine can deliver. Melaika et al. [1] showed the effect of different air inlet restrictors on engine performance of Formula Student car engine using AVL BOOST numerical simulation model and the research was carried out on restrictor diameters, which varied from $15 \mathrm{~mm}$ to $60 \mathrm{~mm}$. The smaller intake manifold pipe diameter increased hydraulic resistance of air intake and worsened therewith cylinder volumetric efficiency that resulted in lower engine power and higher brake specific fuel consumption. Mohamad et al. [2] studied the effect of Ethanol-Gasoline blend fuel on engine power output and emissions. Their results showed great improvement in combustion process and exhaust gas characteristics. Mohamad and Amroune [3] used computational fluid dynamic (CFD) tools to describe the flow effects on engine exhaust chamber acoustic level and showed the transmission loss of muffler at different frequencies using 1D boost solver. Abdullah et al. [4] studied the engine performance in term of fuel consumption. Exhaust emission was influenced by the air intake pressure. The experimental results carried out demonstrated that the air intake pressure was influenced by the degree of opening throttle plate and venturi effect that draws the fuel to the combustion chamber in a carbureted engine. Without the air filter, the combustion process is improved due to a higher air intake pressure that transforms more fuel's chemical energy into heat energy thus raising the exhaust gas temperature above values obtained with an air filter. Mohamad et al. [5] used a transfer matrix method (TMM) to perform the transmission loss of a muffler and the algorithm can also be used for other parts of the exhaust system. The result of their study of an existing muffler was compared with vehicle level test observation data. The transmission loss was optimized for new muffler design, while available literature played an important role in validation of obtained results. Acquati et al. [6] used mass and momentum balance equations to model the airflow and pressure around a nominal operating values computed using mean value models for intake system of a spark ignition engine. As noticed by Winterbone et al. [7], in a regular internal combustion engine (ICE), during the air intake phase (the intake valve open), the cylinder volume is not filled completely, as theoretically wished. This is due to the variation in air density and pressure losses along the feeding system. As a result of this process, real volumetric efficiency of the cylinder and the engine performance as a whole cannot meet the design expectations if all the effects are not considered correctly. A component that plays an important role in this process of air supply is the intake manifold (IM). Its physical characteristics such as pressure loss imposed on air and lack of homogeneity of the loss between the runners (air supply unbalanced) are linked to the efficiency of fuel consumption and engine emissions (Byam et al. [8]).

In the current research, the intake manifold including plenum and channel ducts of Honda CBR 600RR (PC 37) engine (Fig. 1) are identified as components whose parameters are to be improved. 


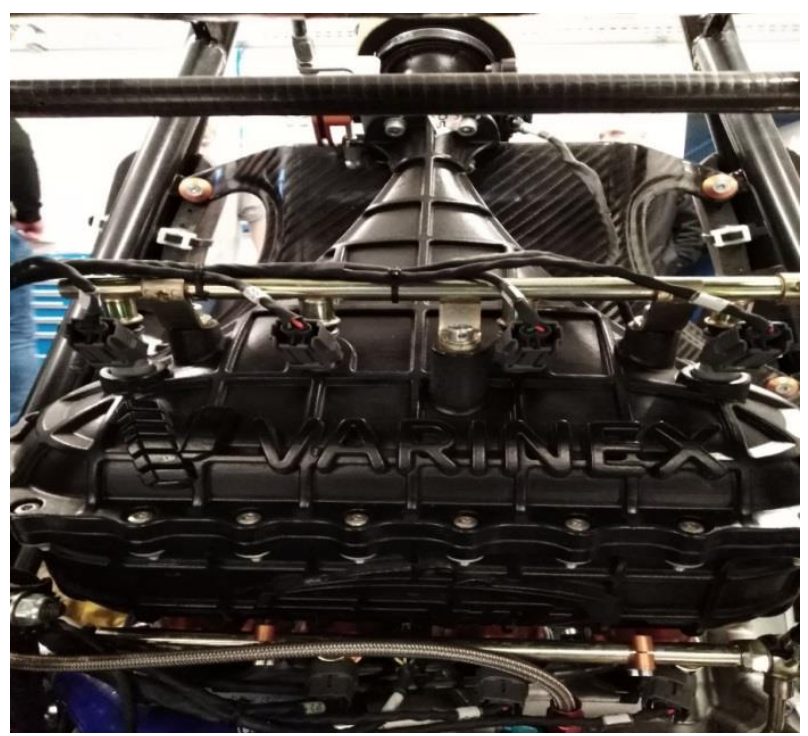

Fig. 1 Honda CBR 600RR (PC 37) intake system

It is rather difficult to obtain the necessary input parameters for CFD analysis necessary for the process of design and optimization, because it is not possible to use a stationary type numerical analysis. For that reason, a 1D model of the intake and exhaust system of the engine was created. The 1D model of the engine was built in AVL-1D Boost Engine Simulation software.

The basic parameters of the air box include the length of the intake discharge pipes (runner) and the total volume of the air box (plenum). Subsequently, the values of the air pressure in the outlets of the plenum are generated based on this software. These values are used as input parameters for the CFD numerical simulation, which is furthermore combined with a geometric optimization to ensure the best final shape of the plenum. The designed process is depicted in Fig. 2.

\section{NUMERICAL ANALYSIS}

To tune the intake runners and determine the ideal runner length for the FS engine, wave theory equations were applied [9], resulting in the following equation for the runner length:

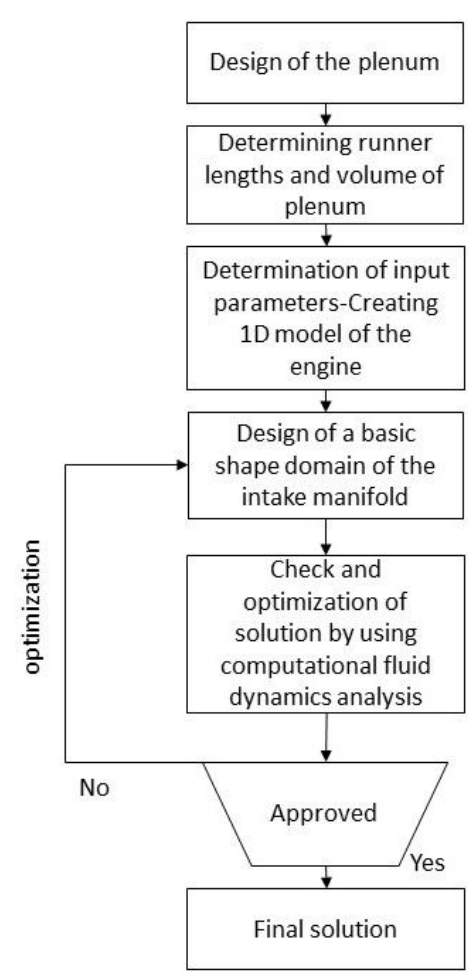

Fig. 2 Flowchart of the design and optimization process 


$$
\text { Runner Length }=\left[\frac{\operatorname{ECD}(0.25)(2) \mathrm{V}_{\mathrm{W}}}{(\mathrm{RPM})\left(\mathrm{R}_{\mathrm{V}}\right)}-\frac{\mathrm{D}}{2}\right]
$$

where RPM is the targeted speed of the engine in revolutions per minute, Rv (reflective value) is the reflected wave $(1,2,3, \ldots n), D$ is the diameter of the runner in $m m, V_{w}$ is the calculated wave velocity in millimeter per second. Effective Cam Duration (ECD) is defined as [10]:

$$
\text { Effective Cam Duration }(E C D)=720^{\circ}-\text { Cam Duration(in degree) }-30^{\circ}
$$

The mass flow rate through restrictor $\left[\mathrm{m}_{\max }\right]$ can be calculated as follows:

$$
\mathrm{m}_{\text {max }}=\mathrm{A}_{\mathrm{r}} \mathrm{P}_{\mathrm{o}} \sqrt{\frac{\mathrm{K}}{\mathrm{RT}_{\mathrm{o}}}}\left(\frac{2}{\mathrm{k}+1}\right)^{\frac{(\mathrm{K}+1)}{2(\mathrm{k}-1)}}
$$

where $A_{r}$ is the area of restrictor $\left[\mathrm{mm}^{2}\right], P_{o}$ is the reference pressure $[\mathrm{Pa}], \mathrm{R}$ is the gas constant equal to $287.04[\mathrm{~J} /(\mathrm{kg} \mathrm{K})], \mathrm{T}_{\mathrm{o}}$ is the reference temperature $[\mathrm{K}], \mathrm{K}$ is the specific heat ratio equal to 1.4 .

The volumetric flow rate, $\mathrm{Q}_{\max }$, can be calculated as follows:

$$
\mathrm{Q}_{\max }=\frac{\mathrm{m}_{\max }}{\rho}
$$

where $\rho$ is the gas density $\left[\mathrm{kg} / \mathrm{m}^{3}\right]$.

The analytical solution for sound pressure level (SPL) of a simple plenum that is considered as an expansion chamber can be obtained by either the potential function method or the transfer matrix method as given in equation below [11]:

$$
\operatorname{SPL}(\mathrm{dB})=20 \log _{10}\left(\frac{\mathrm{P}}{\mathrm{P}_{\mathrm{o}}}\right),
$$

where $\mathrm{P}$ is the pressure $[\mathrm{Pa}]$, while $\mathrm{P}_{\mathrm{o}}$ is the reference pressure $[\mathrm{Pa}]$.

For the 3D flow calculation, the mathematical model is based on the fundamental equations of three-dimensional nonstationary transport: the equations of momentum (Navier-Stokes), energy (Fourier-Kirchhoff) and the conservation of mass (continuity), which take the form of Reynolds after the averaging procedure by the Favre method:

$$
\begin{gathered}
\bar{\rho} \frac{\mathrm{d} \overline{\mathrm{W}_{\mathrm{i}}}}{\mathrm{dt}}=\overline{\mathrm{G}}_{\mathrm{i}}-\frac{\partial \overline{\mathrm{P}}}{\partial \mathrm{x}_{\mathrm{i}}}+\frac{\partial}{\partial \mathrm{x}_{\mathrm{j}}}\left[\mu\left(\frac{\partial \overline{\mathrm{W}}_{\mathrm{i}}}{\partial \mathrm{x}_{\mathrm{j}}}+\frac{\partial \overline{\mathrm{W}}_{j}}{\partial \mathrm{x}_{\mathrm{i}}}-\frac{2}{3} \delta_{\mathrm{ij}} \frac{\partial \overline{\mathrm{W}}_{\mathrm{k}}}{\partial \mathrm{x}_{\mathrm{k}}}\right)-\bar{\rho} \overline{\mathrm{W}^{\prime}} \overline{\mathrm{W}}_{\mathrm{j}}^{\prime}\right], \\
\bar{\rho} \frac{\mathrm{d} \overline{\mathrm{H}}}{\mathrm{dt}}=\overline{\mathrm{G}}_{\mathrm{j}} \overline{\mathrm{W}}_{\mathrm{j}}+\frac{\partial \overline{\mathrm{P}}}{\partial \mathrm{t}}+\frac{\partial}{\partial \mathrm{x}_{\mathrm{i}}}\left(\bar{\tau}_{\mathrm{ij}} \overline{\mathrm{W}}_{\mathrm{j}}\right)+\frac{\partial}{\partial \mathrm{x}_{\mathrm{j}}}\left(\lambda \frac{\partial \overline{\mathrm{T}}}{\partial \mathrm{x}_{\mathrm{j}}}-\mathrm{c}_{\mathrm{p}} \overline{\rho \overline{\mathrm{T}}^{\prime} \mathrm{W}^{\prime}}{ }_{\mathrm{j}}\right), \\
\frac{\partial \bar{\rho}}{\partial \mathrm{t}}+\frac{\partial}{\partial \mathrm{x}_{\mathrm{j}}}\left(\bar{\rho} \overline{\mathrm{W}}_{\mathrm{j}}\right)=0,
\end{gathered}
$$

where $\bar{W}_{i}$ is the averaged velocity along the $x_{i}$-axis $[\mathrm{m} / \mathrm{s}]$, while ${\overline{W^{\prime}}}_{i}^{\prime}$ is the averaged velocity at specific instant of time along the $\mathrm{x}_{\mathrm{i}}$-axis $[\mathrm{m} / \mathrm{s}], \mathrm{t}$ is time $[\mathrm{s}], \overline{\mathrm{P}}$ is the averaged pressure $[\mathrm{Pa}], \overline{\mathrm{G}}_{\mathrm{i}}$ is the component of the density vector of the volume forces along the $\mathrm{x}_{\mathrm{i}^{-}}$ axis $\left[\mathrm{N} / \mathrm{m}^{3}\right], \bar{\rho}$ is the averaged density $\left[\mathrm{kg} / \mathrm{m}^{3}\right], \overline{\mathrm{H}}$ the averaged specific energy $[\mathrm{J} / \mathrm{kg}], \mu$ is the dynamic viscosity $[\mathrm{kg} /(\mathrm{m} \mathrm{s})], \mathrm{c}_{\mathrm{p}}$ the heat capacity at constant pressure $[\mathrm{J} /(\mathrm{kg} \cdot \mathrm{K})], \lambda$ is the thermal conductivity $[\mathrm{W} /(\mathrm{m} \mathrm{K})], \delta_{\mathrm{ij}}$ is the Kronecker symbol, $\bar{\tau}_{\mathrm{ij}}$ is the averaged Reynolds stress component, $\bar{\rho}{\overline{W^{\prime}}}_{\mathrm{i}} \overline{\mathrm{W}}^{\prime}{ }_{\mathrm{j}}$ is the Reynolds tensor, $\overline{\mathrm{T}}$ is the averaged temperature $[\mathrm{K}]$ and $\overline{\mathrm{T}}^{\prime}$ is the averaged temperature at specific instant of time [K]. In the above equation, the Einstein summation rule is used for the twice repeated $\mathrm{i}, \mathrm{j}$ and $\mathrm{k}$ indices. 
The system of transport equations in the Reynolds form (6) is closed by the k- $\varepsilon-\zeta-f$ model of turbulence specially developed and verified for the processes of flow, combustion, and heat transfer in piston engines [12, 13]. It consists of three equations: for the k kinetic energy of turbulence, for the $\varepsilon$ dissipation rate of this energy known from the k- $\varepsilon$ model of turbulence, and the equations for the normalized velocity scale $\zeta=\overline{\mathrm{W}}^{2} / \mathrm{k}$. The $\mathrm{k}-\varepsilon-\zeta-\mathrm{f}$ turbulence model proposed by Hanjalic et al. [14] contains the Durbin elliptical function of $\mathrm{f}$, which takes into account the near-wall anisotropy of turbulence.

System of Eqs. (6) is used to describe, respectively, the flow velocities (Navier-Stokes equation), the enthalpy (energy equation) and the mass or density (continuity equation) for each control volume of the considered computational domain. The wall heat transfer is determined through the thickness of the boundary layer using hybrid wall function [15].

We also emphasize that this mathematical model is typical for CFD calculations of processes in piston engines and it is described in detail by Merker et al. [16], Basshuysen and Schäfer [17], Kavtaradze et al. [18].

\section{DEVELOPMENT OF CAE MODEL}

The 3D model of base FS race car intake system was sketched based on specific prototype engine using advanced design software Creo 4.0, including restrictor, inlet ducts, connected to outlet plenum and runner. The cross section and the dimensions of intake manifold are depicted in Fig. 3.
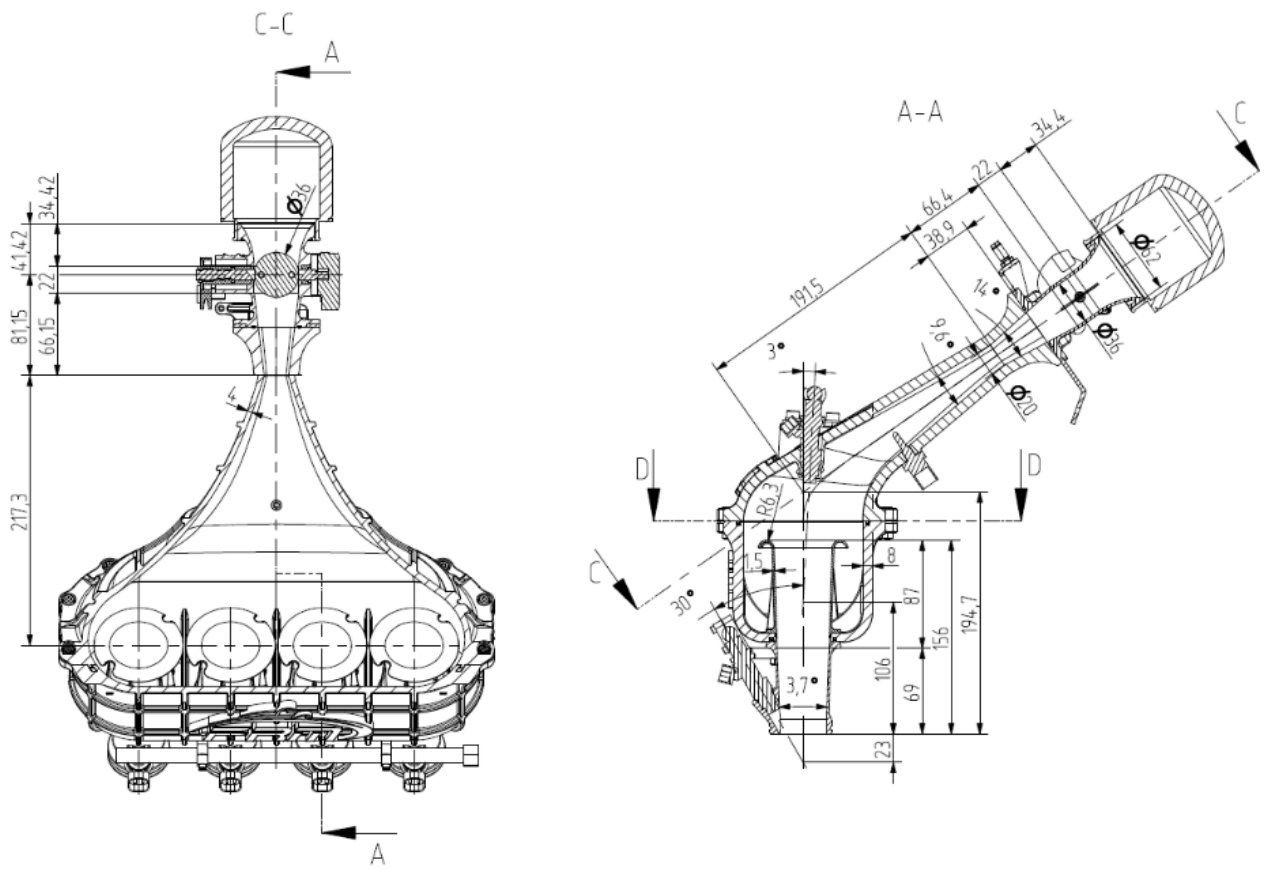

Fig. 3 FS race car engine intake system dimensions 
This study was performed using manufacturing data of a four stroke four cylinders Honda CBR 600RR (PC 37) SI engine. The detailed specification of the base engine selected for the simulation is given in Table 1.

Table 1 The specification of the base engine

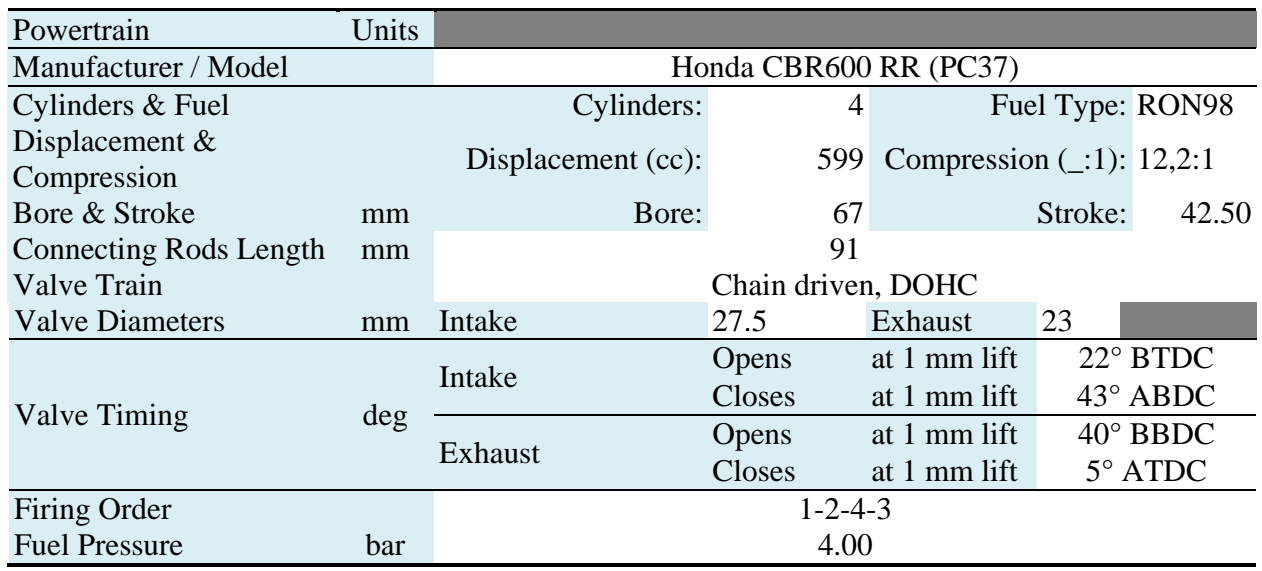

Most of the places in the frame consisted of mating parts that had a small gap. In order to bridge that gap and make them air tight, the bridging process had to be done on each part, followed by capping the ducts. The inner volume was extracted from the solid model by means of design software Solidworks. The intake restrictor and runner designs were explored using computational fluid dynamics (CFD) flow modeling software to analyze and visualize fluid flow during the design process.

\section{ANALYTICAL BACKGROUND}

The shape optimization of the plenum is done using CFD simulation (solver 3D Fire Advanced Flow). For the purpose of simulation and geometrical optimization of the plenum, the intake manifold was meshed with overall 3115552 elements. Some basic parameters and characteristics of the model are provided in Table 2.

Table 2 Model properties

\begin{tabular}{ll}
\hline Type of model & 3D \\
Type of mesh & Mapped \\
Total number of elements & 3115552 \\
Volume of model & $0.004449 \mathrm{~m}^{3}$ \\
Surface area & $0.346168 \mathrm{~m}^{2}$ \\
\hline
\end{tabular}

All obtained geometric parameters of the intake manifold and other parts of the engine from the 3D scan were entered into the 1D model (such as variable diameters of the intake and exhaust pipes dependent on their length, angles in the pipe joints of the intake and exhaust manifold, materials with thermal properties, etc.). Boundary condition 
were set according to the engine operation, and for the air flow through restrictor to the runner $\mathrm{k}-\mathrm{e}-\zeta$-f model was set as a turbulence model in order to treat the turbulence regime in the present study, including nearly random fluctuations in velocity and pressure in both space and time.

A 1D model of the engine was created to obtain the input data for CFD analysis (Fig. 4).

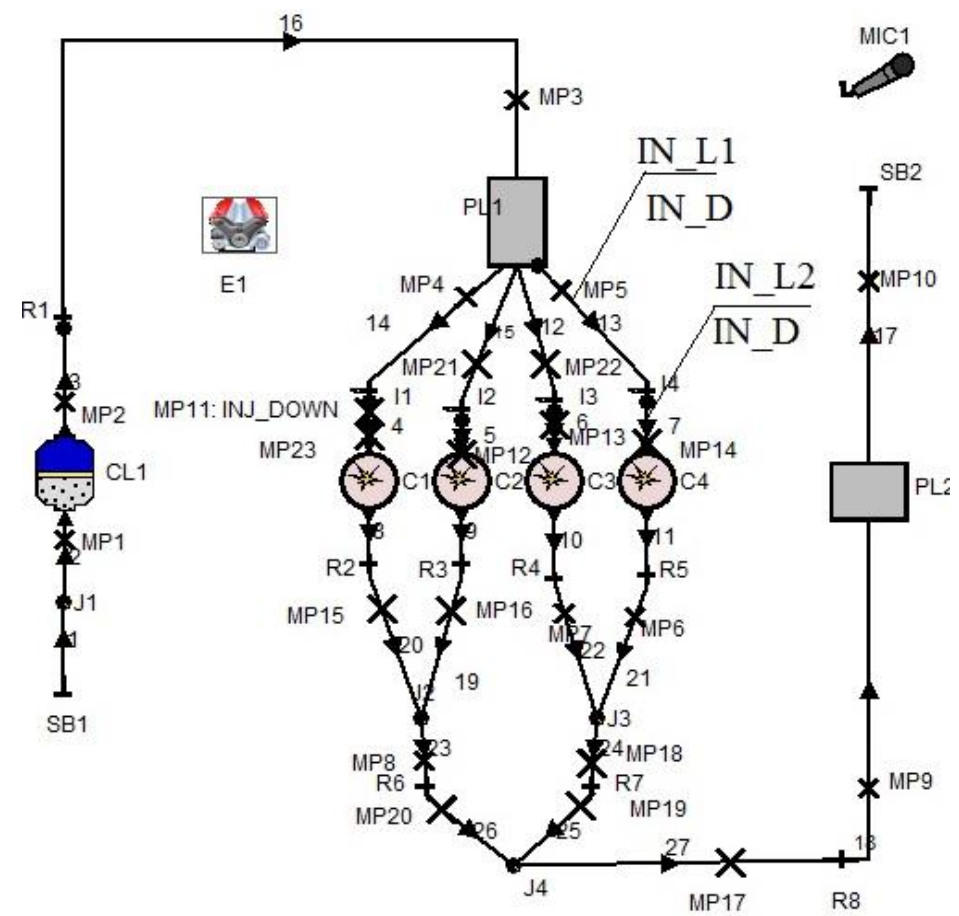

Fig. 4 1D model of the Honda CBR 600RR (PC 37) engine

Values of pressures and temperatures for the individual cylinders of the engine in relation to time were subsequently generated from the 1D model. These values are used as input for the CFD analysis. The final analysis was performed as transient for complete cycles of the engine. Several simulations of the engine were done to find the most appropriate length of the runner pipes for the whole operating speed range of the engine. More specifically, for the optimal length of the runner pipes was searched in the range 150-300 $\mathrm{mm}$, while for the optimal total volume of the plenum in the range 2-4 liters.

\section{RESULTS}

Software calculations and multi-iterations showed that a short runner has a negative effect onto the air delivery. With the current design, the airflow would be turbulent when entering the cylinder, and thus decrease the power delivered by the engine (Fig. 5). 


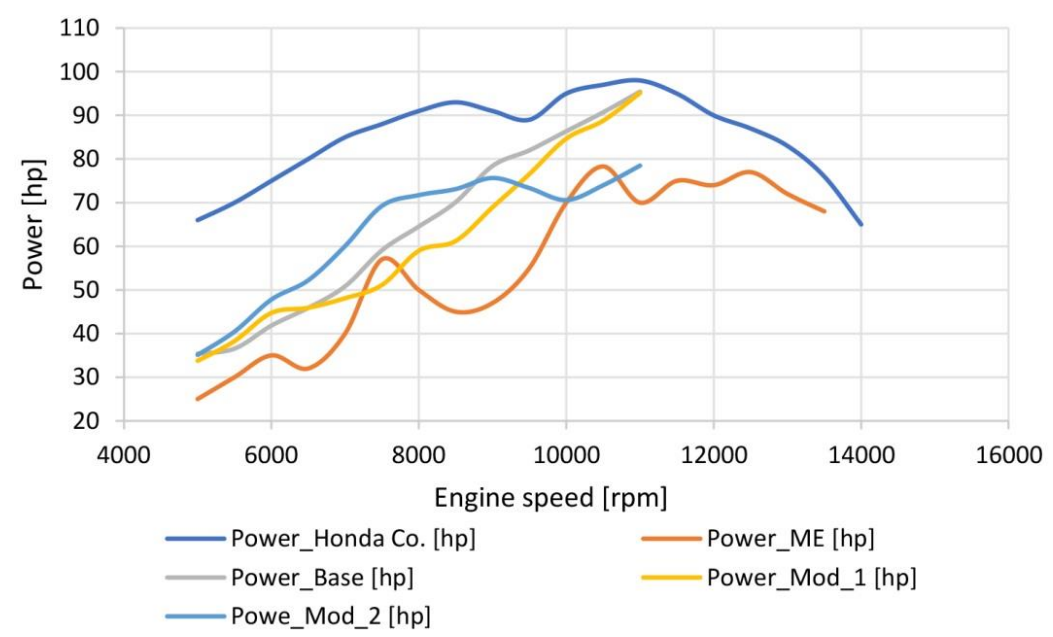

Fig. 5 Comparison of power output from Honda Co., ME workshop test with the base case, and in the modifications 1 and 2 from software

In the version denoted as Modified 1, the diameter of the inlet channel IN_D was increased from 33.5 to $42 \mathrm{~mm}$ (see engine scheme, Fig. 4), and the volume of the intake manifold PL1 was decreased from 4 to 2 liters. In the version denoted as Modified 2, the length of inlet port IN_L1 was increased from 100 to $250 \mathrm{~mm}$, IN_D diameter was reduced from 33.5 to $32 \mathrm{~mm}$, and PL1 volume was reduced from 4 to 3 liters.

The results show that long runners provide high torque at low rpm of the engine and short runners are advantageous at high engine speeds. In terms of the size of the plenum, a small plenum volume provides better throttle response, but a large volume plenum allows high power of the engine, Fig. 6.

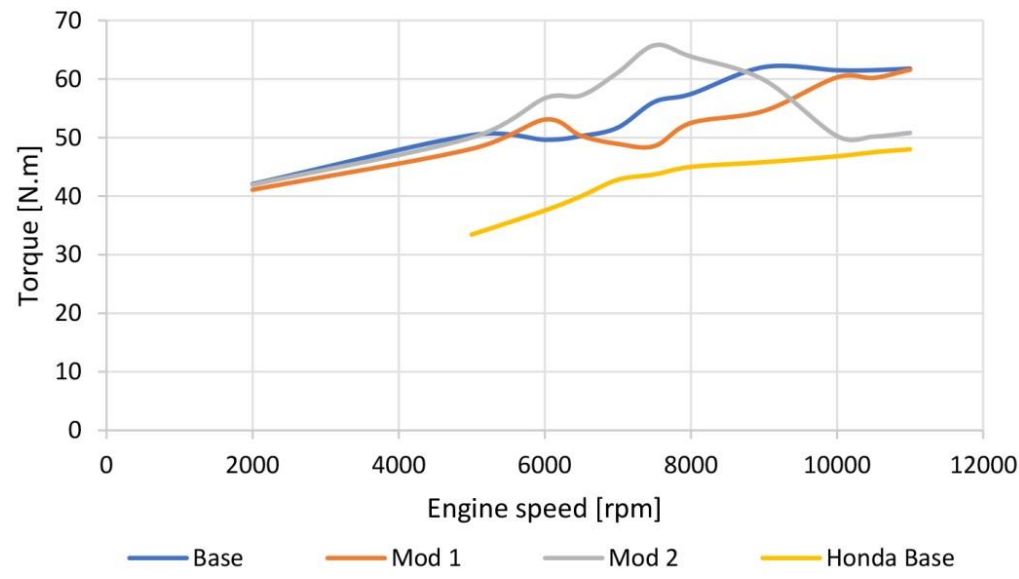

Fig. 6 Comparison of torque output from Honda Co., ME workshop test with the base case, and in the modifications 1 and 2 from software 
The changes were carried out as a step-by-step search of options with different diameters, volumes and lengths. The optimality criterion was the effective performance of the engine at different operating modes (5000-11000 rpm). However, this optimization was performed under procedure in manual mode (search of optimal sizes with the use of Case Sets). It was not done completely automatically using Boost optimizer. The analytical solution of sound pressure level (SPL) of a simple plenum was performed and optimized based on intake system geometry modification. Details are given in Fig. 7.

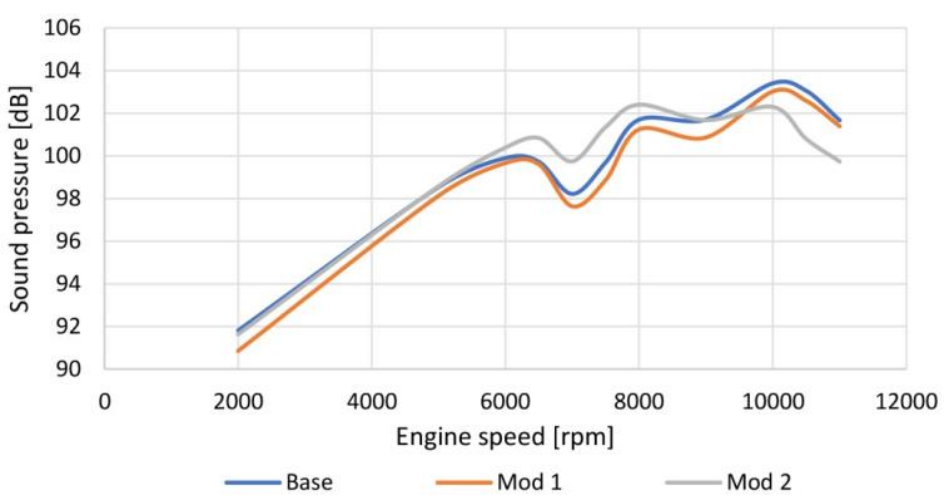

Fig. 7 Comparison of sound pressure output from Honda Co., ME workshop test with the base case, and in the modifications 1 and 2 from software

This type of analysis is rather difficult because it involves high speed compressible airflow in the intake system, pressure drops and changes of temperatures. The final distribution of the velocities, pressures and the mass flows of the air in the air box are given in Fig. 8. The values are evaluated at the outlets of the pipes of the plenum for one operational cycle of the engine (rotation of the crankshaft $720^{\circ}$ ) at $8000 \mathrm{rpm}$. The initial conditions were the temperature and pressure inside the calculated volume at the initial moment of calculation (the data were taken from the calculation results in Boost).

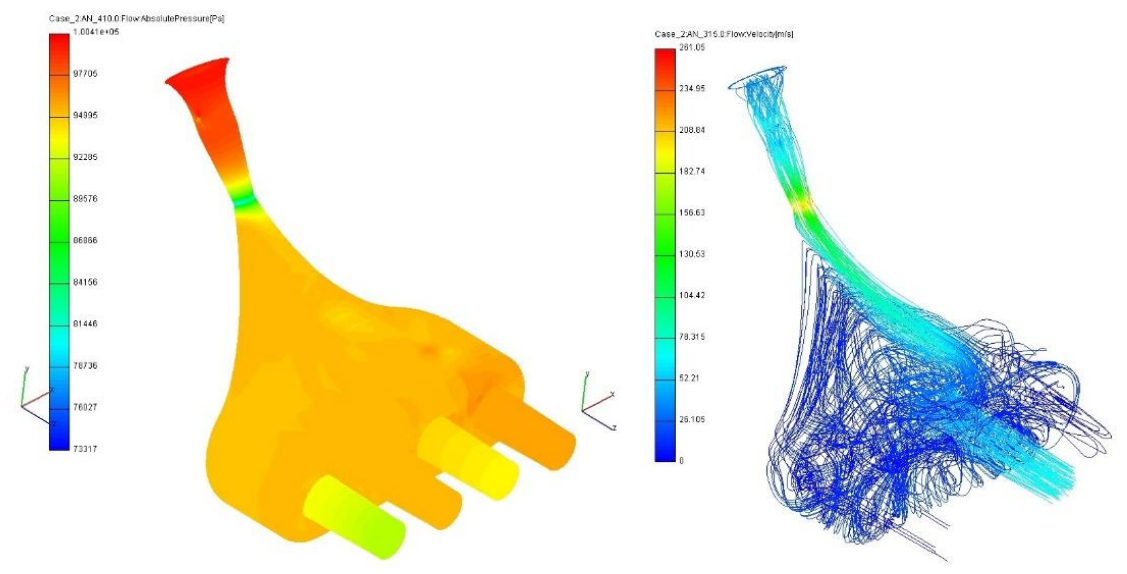

Fig. 8 Left: Pressure contour, Min=73317, Max=1.0041e+05 Pa at 8000 rpm; Right: Velocity streamline Min=, $\operatorname{Max}=261.05 \mathrm{~m} / \mathrm{s}$ at $8000 \mathrm{rpm}$ 
The pressure drop was defined as the difference between the pressure in the exhaust manifold at the cylinder outlet and the cross section at the outlet of the computational volume.

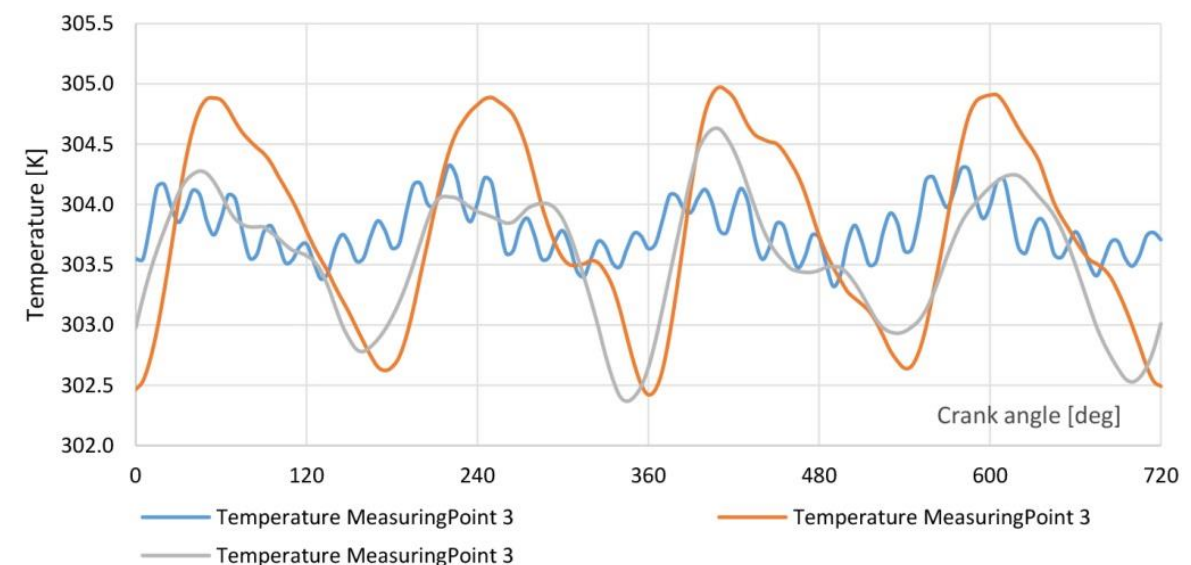

Fig. 9 Temperature variation at restrictor of the intake system at 2000, 5000 and $8000 \mathrm{rpm}$

\section{CONCLUSIONS}

The team from University of Miskolc improved the car's air intake system using 1DAVL Boost within the parametric Fire software Workbench environment. FS regulations limit the minimum diameter of the restrictor to $20 \mathrm{~mm}$, which regulates the maximum intake mass flow rate. The plenum, downstream of the restrictor, directly influences the amount of fresh air reaching the cylinders. A plenum that is too large causes the motor to react too slowly to the accelerator and, in combination with short suction pipes, triggers the engine to develop sufficient torque only at high rotation speeds. A too small plenum behaves oppositely. Using the equation for the intake runner length, the length of the ideal runner was determined to be approximately $250 \mathrm{~mm}$ and with a diameter of $32 \mathrm{~mm}$. Hence, design II of Formula Student Racing is a better choice.

Acknowledgement: The authors thank Formula Racing Miskolc for assistance with design technique, methodology, and Dr. Faik Hamad, Teesside University in Middlesbrough, for comments that greatly improved the manuscript.

\section{REFERENCES}

1. Melaika, M., Rimkus, A., Vipartas, T., 2017, Air restrictor and turbocharger influence for the formula student engine performance, Procedia Engineering, 187, pp. 402-407.

2. Mohamad, B., Szepesi, G., Bollo, B., 2018, Review Article: Effect of ethanol-gasoline fuel blends on the exhaust emissions and characteristics of SI engines, Vehicle and Automotive Engineering, 2, pp. 29-41.

3. Mohamad, B., Amroune, S., 2019, The analysis and effects of flow acoustic in a commercial automotive exhaust system, Advances and Trends in Engineering Sciences and Technologies III, Proceedings of the 3rd International Conference on Engineering Sciences and Technologies (ESaT 2018), September 12-14, 2018, High Tatras Mountains, Tatranské Matliare, Slovak Republic, pp. 197-202. 
4. Adbulleh, N.R., Shahruddin, N.S., Mamat, A.M.I., Kasolang, S., Zulkifli, A., Mamat, R., 2013, Effects of air intake pressure to the fuel economy and exhaust emissions on a small SI engine, Procedia Engineering, 68, pp. 278-284.

5. Mohamad, B., Karoly, J., Kermani, M., 2019, Exhaust system muffler volume optimization of light commercial passenger car using transfer matrix method, International Journal of Engineering and Management Sciences (IJEMS), 4, 132-139.

6. Acquati, F., Battarola, L., Scattolini, R., Siviero, C., 1996, An intake manifold model for spark ignition engines, IFAC Proceedings, 29(1), pp. 7945-7950.

7. Winterbone, E., Pearson, R., Horlock, J., 2000, Theory of engine manifold design: wave action methods for IC engines, Professional Engineering Publ. London.

8. Byam, B., Fsadni, J., Hart, A., Lanczynski, R., 2006, An experimental approach to design, build, and test a throttle body and restrictor system for Formula SAE racing, SAE Technical Paper 2006-01-0748, SAE World Congress, Detroit, MI, USA.

9. FSAE MQP, 2011, Retrieved from: http://moorsportsspares.com/file/2011_ttx25mkii_e.pdf (last access: 15.07.2019)

10. Jawad, B., Lounsbery, A., Hoste, J., 2001, Evolution of intake design for a small engine formula vehicle, SAE Technical Paper, 2001-01-1211, SAE World Congress, Detroit, MI, USA.

11. Shelagowski, M., Mahank, T., 2015, CFR Formula SAE intake restrictor design and performance, Proceedings of the 2015-ASEE North Central Section Conference American Society for Engineering Education.

12. Tatschl, R., Schneider, J., Basara, D., Brohmer, A., Mehring, A., Hanjalic, K., 2005, Progress in the 3DCFD calculation of the gas and water side heat transfer in engines, in 10. Tagung der Arbeitsprozess des Verbrennungsmotors (Proc. 10th Meeting on the Working Process of the Internal Combustion Engine), Graz, Austria.

13. Tatschl, R., Basara, B., Schneider, J., Hanjalic, K., Popovac, M., Brohmer, A., Mehring, J., 2006, Advanced turbulent heat transfer modeling for IC-engine applications using AVL FIRE, Proceedings of International Multidimensional Engine Modeling User's Group Meeting, Detroit, USA.

14. Hanjalic, K., Popovac, M., Hadziabdic, M., 2004, A robust near-wall elliptic-relaxation eddy-viscosity turbulence model for CFD, International Journal of Heat and Fluid Flow, 25(6), pp. 1047-1051.

15. Popovac, M., Hanjalic, K., 2005, Compound wall treatment for RANS computation of complex turbulent flow, Proc. 3rd M.I.T. Conference, Boston, USA

16. Merker, G., Schwarz, Ch., Teichmann R., 2019, Grundlagen Verbrennungsmotoren: Funktionsweise, Simulation, Messtechnik, 9th ed, Springer, Wiesbaden. P. 1117.

17. Basshuysen, R., Schäfer, F., 2007, Handbuch Verbrennungsmotor, Vieweg und Sohn Verlag, Wiesbaden, p. 1032.

18. Kavtaradze, R.Z., Onishchenko, D.O., Zelentsov, A.A., Sergeev, S.S., 2009, The influence of rotational charge motion intensity on nitric oxide formation in gas-engine cylinder, International Journal of Heat and Mass Transfer, 52(19-20), pp. 4308-4316. 